\title{
Optical properties of $\mathrm{SnO}_{2}-\mathrm{As}_{2} \mathrm{Se}_{3}-\mathrm{ZnS}(\mathrm{Mn}, \mathrm{Cu})$-Al structure with intermediate chalcogenide-glass layer
}

\author{
N.Mateleshko, V.Mitsa, S.Sikora \\ Department of Solid State Electronics, Uzhgorod State University, 32 Voloshin Str., \\ 88000 Uzhgorod, Ukraine, e-mail: mitsa@univ.uzhgorod.ua
}

Received: 05.05.2003

\begin{abstract}
Introducing of $\mathrm{As}_{2} \mathrm{Se}_{3}$ as a contrasting intermediate layer into $\mathrm{SnO}_{2}-\mathrm{As}_{2} \mathrm{Se}_{3}-\mathrm{ZnS}(\mathrm{Mn}, \mathrm{Cu})-$ Al structure allows one to increase 1.5 times the light contrast range of the device that facilitates the perception of symbol-alphabetic information. The bleaching of $\mathrm{As}_{2} \mathrm{Se}_{3}$ film under the action of moisture allows to control the state of the structure air-tightness. The absorption edge of As-Se film and the electrooptical characteristics of $\mathrm{SnO}_{2}-\mathrm{ZnS}(\mathrm{Mn}, \mathrm{Cu})-$ $\mathrm{Al}$ active structure are investigated.
\end{abstract}

Key words: Electroluminescence, $\mathrm{ZnS}$ powder, thin film, chalcogenide glasses

PACS: 78.40.-q, 78.60.Fi

\section{Introduction}

Electroluminescent direct-current flat panels (EDCFP) occupy an important place in developing modern means of representation [1]. One of the disadvantages of powder EDCFP is their relatively low light contrast range and a decrease of brightness with time [2-3]. Special contrasting substrates increase the contrast range, resulting simultaneously in considerable losses of $\mathrm{SnO}_{2}-\mathrm{ZnS}(\mathrm{Mn}, \mathrm{Cu})-\mathrm{Al}$ structure radiation. The aim of this work is to investigate the possibilities for using As-Se high-ohmic chalcogenide glasses ( $\mathrm{GhG}$ ) as an intermediate contrasting layer in $\mathrm{SnO}_{2}-\mathrm{As}_{2} \mathrm{Se}_{3}-\mathrm{ZnS}(\mathrm{Mn}, \mathrm{Cu})-\mathrm{Al}$ structure and for the visual inspection of airtightness of electroluminescent flat panels for the data representation.

\section{Experimental Technique}

The layer $\mathrm{As}_{2} \mathrm{Se}_{3}$ in the $\mathrm{SnO}_{2}-\mathrm{As}_{2} \mathrm{Se}_{3}-$ $\mathrm{ZnS}(\mathrm{MnCu})-\mathrm{Al}$ structure was prepared by a vacuum flash evaporation at 773 and $873 \mathrm{~K}$ onto a glass substrate coated by conducting transparent $\mathrm{SnO}_{2}$ layer, as a preliminary electrolumine- scent layer of powder $\mathrm{ZnS}$ with the thickness of $5 \times 10^{4} \mathrm{~nm}$ was deposited by the method of stenciling $[4,5]$. The upper aluminum electrode was formed with the vacuum evaporation. Optical investigations of the absorption edge of As-Se films were carried out by a conventional method, with the measurements of both reflection and transmission. The electrooptical measurements were carried out in accordance with the generally accepted methods.

\section{Results and discussions}

The data for the absorption edge of the films of $\mathrm{As}_{\mathrm{x}} \mathrm{Se}_{100-\mathrm{x}}$ system show that in the region of $\alpha>10 \mathrm{~cm}^{-1}$ ( $\alpha$ is absorption coefficient) the dependence $\alpha$ versus the energy of photons may be described by a relationship $\alpha=\left(h v-E_{0}\right)^{2}\left(E_{o}\right.$ being the pseudo-energy gap) typical for chalcogenide vitreous semiconductors.

The concentration changes $\mathrm{E}_{\mathrm{o}}$ for the As-Se films prepared at different temperatures are given in Fig. 2. The absorption edge of the films below $\alpha<10^{3} \mathrm{~cm}^{-1}$ is described by the relationship $\alpha \sim \exp (h v / S)$, where $S$ is the absorp- 


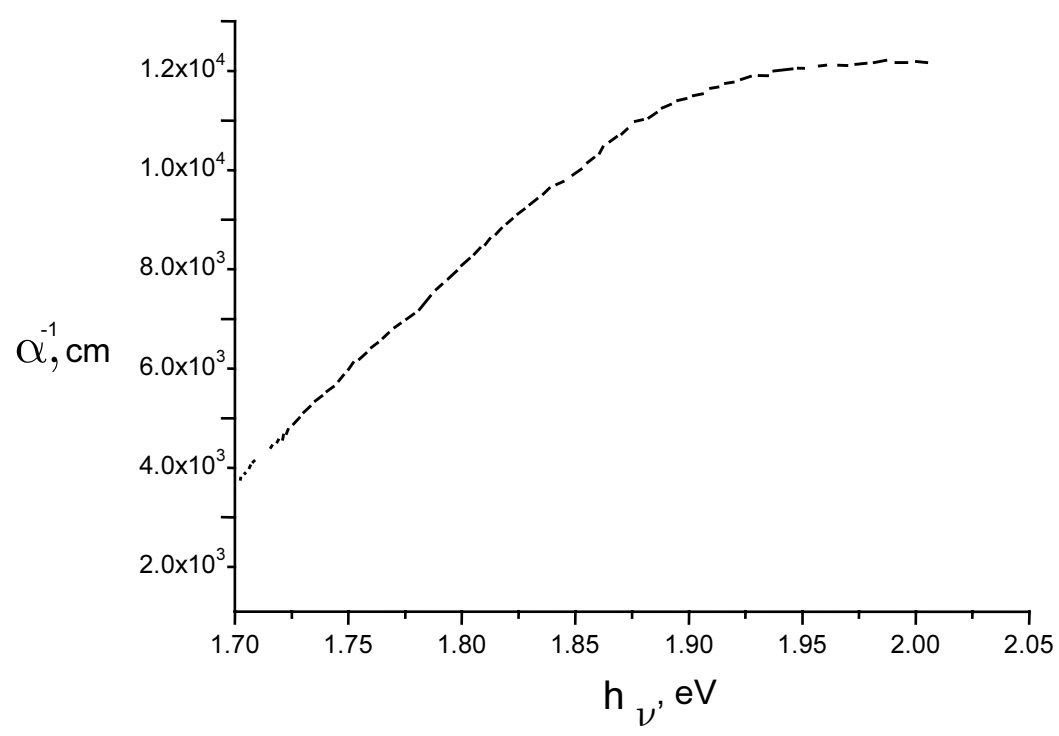

Fig. 1. Absorption coefficient versus photon energy for the $\mathrm{As}_{2} \mathrm{Se}_{3}$ film prepared at $773 \mathrm{~K}$.

tion edge slope [3]. $\mathrm{As}_{2} \mathrm{Se}_{3}$ has the sharpest edge that allows one to limit the background diffuse-mirror reflection from $\mathrm{SnO}_{2}-\mathrm{As}_{2} \mathrm{Se}_{3}-\mathrm{ZnS}(\mathrm{Mn}, \mathrm{Cu})-\mathrm{Al}$ structure in the region of wavelengths $\lambda<500 \mathrm{~nm}$, due to a high diffuse reflection $(\rho=0.88)$ of the powder $\mathrm{ZnS}$. The measurements of the diffuse-mirror reflection show that introduction of $\mathrm{As}_{2} \mathrm{Se}_{3}$ as an intermediate layer causes a decrease by 1.5 times in the reflection $\rho$, when compare with the powder $\mathrm{ZnS}(\mathrm{Mn}, \mathrm{Cu})$. The calculations testify that the decrease in the background reflection from the structure with $\mathrm{As}_{2} \mathrm{Se}_{3}$ layer results in the brightness contrast $(\mathrm{K})$ half as much again, in comparison with the $\mathrm{K}$ value for the structure without a contrasting intermediate layer based on ChG.

Introducing the $\mathrm{As}_{2} \mathrm{Se}_{3}$ layer into the structure causes the decrease of brightness $\Delta \mathrm{B} \leq 10 \%$. This is less than the decrease in the intensity of spectral contrasting substrate. The latter decreases two times the structure radiation [3].

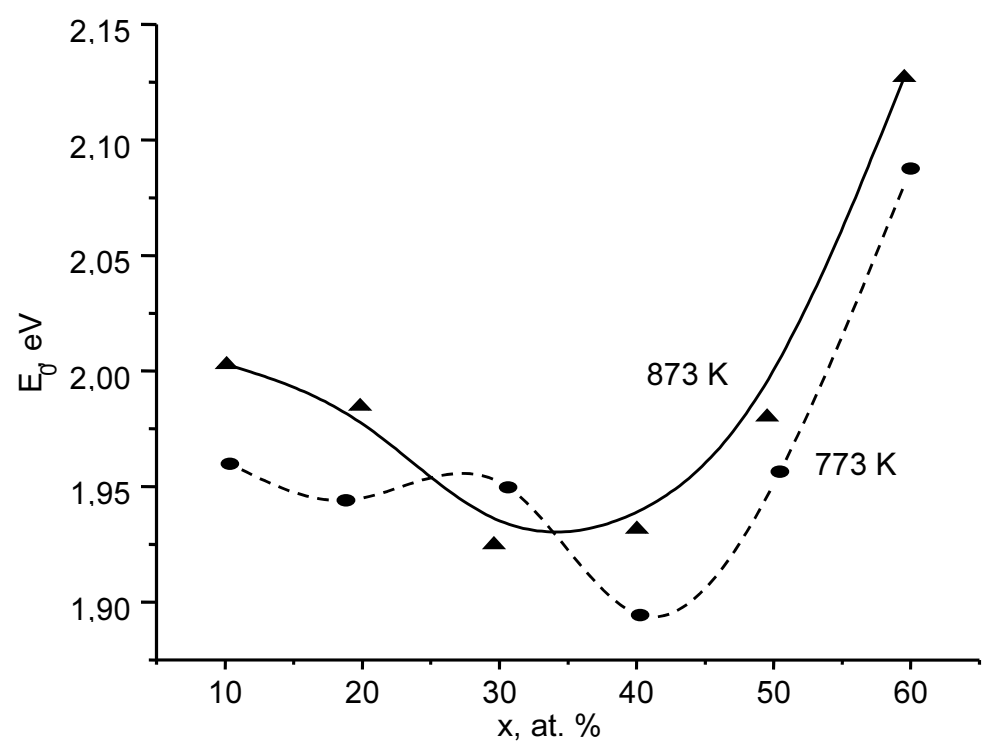

Fig. 2. Concentration changes of the energy gap for $\mathrm{a}-\mathrm{As}_{2} \mathrm{Se}_{3}$ films produced at different temperatures of evaporator (the corresponding temperatures are indicated near the curves). 


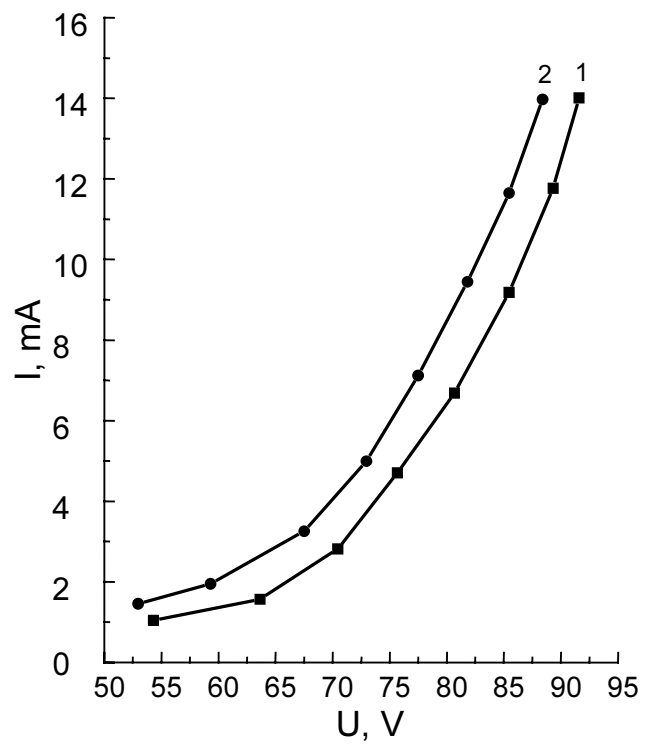

a)

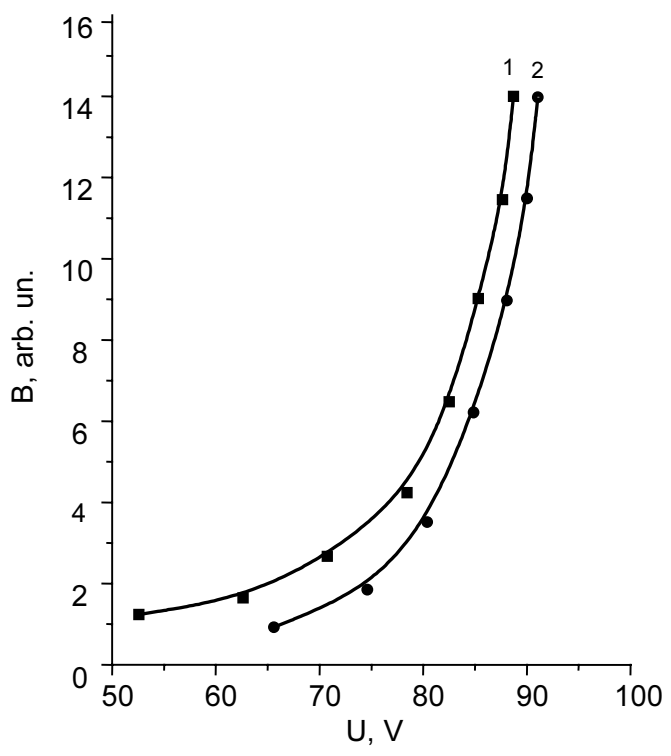

b)

Fig. 3 Volt-ampere (a) and volt-brightness (b) characteristics of the structures: 1 - $\mathrm{SnO}_{2}-\mathrm{ZnS}(\mathrm{Mn})-\mathrm{Al}, 2-\mathrm{SnO}_{2}-\mathrm{As}_{2} \mathrm{Se}_{3}-\mathrm{ZnS}(\mathrm{Mn})-\mathrm{Al}$.

The measurement of voltage-current and voltage-brightness characteristics demonstrate (see Fig. 2) that the introduction of the dielectric $\mathrm{As}_{2} \mathrm{Se}_{3}$ layer into the structure does not change the appearance of the voltage-current characteristics $\left(I \sim U^{\mathrm{n}}, n=6-8\right)$ and shifts them both towards the region of higher voltages only (Fig. 3).

Thus, the introduction of $\mathrm{As}_{2} \mathrm{Se}_{3}$ layer into the active $\mathrm{SnO}_{2}$ structure increases 1.5 times its light contrast range and does not practically change the electrooptical characteristics.

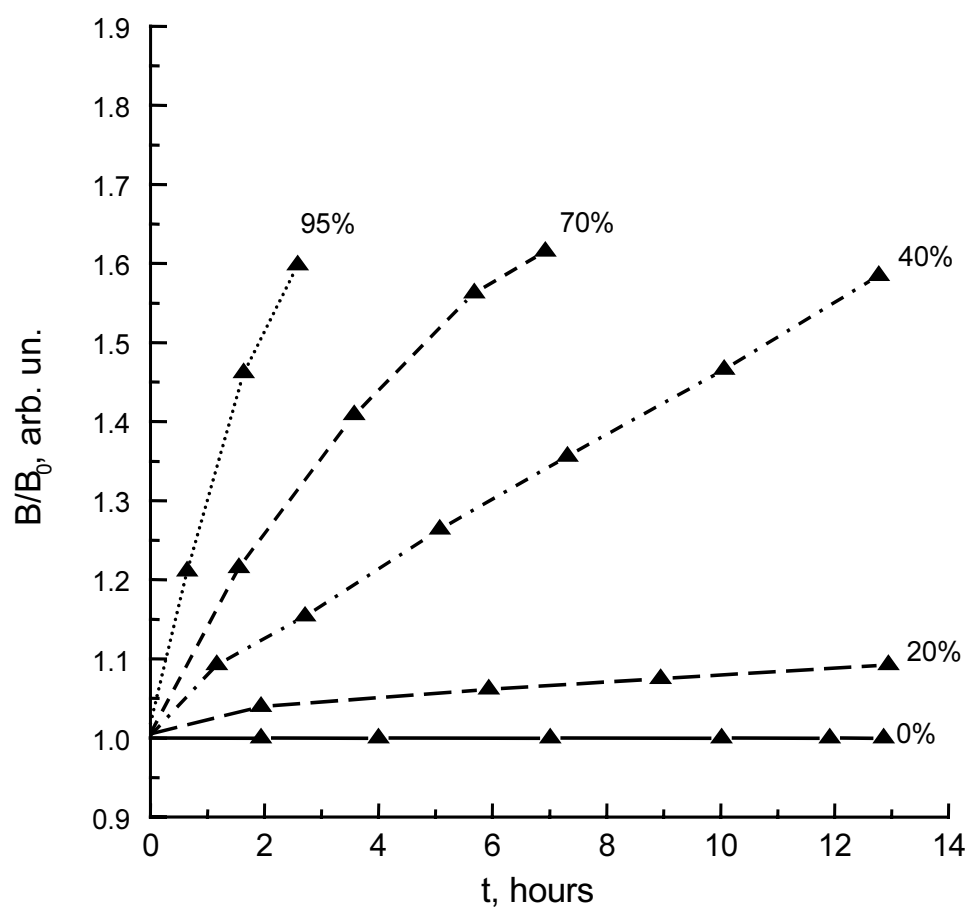

Fig. 4 Change in the radiation intensity of the electroluminescent direct-current structure with moisture (\%). 
The "durability" of the data-representation electroluminescent flat devices is limited by a decay of electro-luminophore layer. The influence of moisture due to depressurization is considered to be one of the possible reasons for decrease in the glow brightness [2,3]. While placing the depressurized $\mathrm{SnO}_{2}-\mathrm{As}_{2} \mathrm{Se}_{3}-\mathrm{ZnS}(\mathrm{Mn})-\mathrm{Al}$ structure into the chamber with different moisture characteristics, the bleaching of $\mathrm{As}_{2} \mathrm{Se}_{3}$ film has been observed. The nature of photo-bleaching is associated with the electro-stimulated optical changes described in [6]. The dynamics of the brightness changes depending on the moisture is given in Fig. 4.

The data for the bleaching of $\mathrm{As}_{2} \mathrm{Se}_{3}$ film under the action of moisture allows one to inspect the state of air-tightness of the structure.

\section{References}

1. Alexander P.W., Sherhod C., Stowell M.S. J. Phys. D. Appl. Phys. 1211635 (1988).

2. Vecht A. J. Vac. Sci. Technol. 10789 (1973).

3. Sikora S.I., Svechnikov S.V., Mitsa V.M., Vashchuk F.H. Scientific Herald of Uzhgorod institute of informatic, economic and law. 265 (1998) (in Ukrainian).

4. Sikora S.I., Mitsa V.M., Nadoshi T.I. Radioel. Probl. Series. Gen. Probl. of Radioel. 2134 (1991) (in Russian).

5. Sikora S.I., Mitsa V.M., Nadoshi T.I. Radioel. Probl. Series. Gen. Probl. of Radioel. 1932 (1991) (in Russian).

6. Tsiulyanu D.I., Chumakov I.S., Hrynshpun L.B. Phys. and Tech. of Semicond. 1721968 (1983) (in Russian). 